\title{
ESTUDO DO COEFICIENTE DE PERFORMANCE (COP) DO SISTEMA DE RESFRIAMENTO EVAPORATIVO UTILIZANDO HIDROEJETOR
}

\author{
C. C. M. de OLIVEIRA ${ }^{1}$, M. C. GUTIERREZ ${ }^{1}$ e V. SILVEIRA Jr ${ }^{1}$ \\ ${ }^{1}$ Universidade Estadual de Campinas, Departamento de Engenharia de Alimentos \\ E-mail para contato: cintiamelgaco@ hotmail.com
}

\begin{abstract}
RESUMO - A busca por sistemas de refrigeração eficientes e acessíveis é crescente no mercado. Este trabalho teve como objetivo avaliar energeticamente um sistema de resfriamento evaporativo com uso de hidroejetor. Após o funcionamento do sistema avaliou-se o coeficiente de desempenho de acordo com as diferentes potências térmicas aplicadas no reservatório de resfriamento. Nas condições operacionais nominais $4,1 \pm 0,1 \mathrm{~m}^{3} / \mathrm{h}$ e $5 \pm 0,5{ }^{\circ} \mathrm{C}$, o coeficiente de desempenho (COP) avaliado no sistema na maior inserção de potência térmica, 92,27 W pela água de resfriamento, foi de 0,077 , sendo subestimado devido a ineficiência da bomba centrifuga. $\mathrm{O}$ sistema em estudo não foi ideal para resfriamento de fluido a baixas temperaturas nas condições operacionais estudadas, mas pode ser muito bom quando utilizado para resfriamento de fluido a patamares de temperatura maior, podendo ser complementar ou substituto ao sistema de refrigeração principal.
\end{abstract}

\section{INTRODUÇÃO}

Indústrias e pesquisadores estão em busca de sistemas de refrigeração cada vez mais eficientes e econômicos. Com esse objetivo está surgindo no mercado equipamentos que modificam o sistema de refrigeração convencional ou são combinados a ele para aumentar a sua eficiência e viabilidade.

Uma alternativa de um sistema de resfriamento com custo viável é o evaporativo com uso de ejetores. Estes são dispositivos simples, regido pelo princípio de Bernoulli, em que, pela vazão de ar, água ou vapor, como fluidos de circulação que passam em seu interior, produz uma queda de pressão que pode ser aproveitada para succionar os vapores do refrigerante primário e então evaporá-lo e resfriá-lo. O resfriamento ocorre devido ao princípio natural em que há a retirada de calor sensível do fluido pela sua evaporação (entalpia de vaporização).

Sistemas de resfriamento evaporativo com uso de ejetores a vapor são os mais utilizados, apresentando meios para dimensionamento como também vários estudos com detalhes de suas geometrias estimadas com ajuda de software. Já o uso de ejetores utilizando água líquida como fluido de circulação no seu interior, hidroejetores, são pouco utilizados, o que indagou a obter novos conhecimentos a respeito do seu comportamento, permitindo a possibilidade de criar um sistema de resfriamento simples e aplicável em locais com abundância de água em circulação, existentes ou produzida com baixos investimentos.

Sistemas de resfriamento evaporativo com uso de hidroejetor são aplicáveis em propriedades 
rurais ou industriais que apresentem, no seu território, abundância de escoamento de recursos hídricos. Dependendo da forma que esse recurso estiver disponível na propriedade, o sistema em estudo pode produzir o resfriamento sem utilização extra de energia elétrica, por exemplo, com o aproveitamento do escoamento da água existente a ser utilizado para produção de baixa pressão.

O sistema de resfriamento evaporativo com uso de hidroejetor pode ser utilizado, dentro de limitadas condições, para substituir sistemas de refrigeração convencional, bombas de vácuo, ejetores a vapor, entre outros, onde haja circulação ou escoamento do fluido para ser aproveitado ou implementado para determinadas condições operacionais. É um sistema de baixo investimento financeiro e tem apelo sustentável, não gerando qualquer tipo de resíduo para o meio ambiente. Ele utiliza fluido refrigerante não tóxico, não inflamável, não possui potencial carcinogênico e ainda é um recurso abundante no país, a água.

O sistema estudado pode ser utilizado para resfriamento de uma aplicação qualquer com contato indireto do meio com a água resfriada no sistema. Diferente dos trabalhos de Rodrigues et al. (2012) e Cavalheiro et al. (2012) que trabalharam com o contato direto do vácuo sobre o alimento para arrefecimento do mesmo, a água que é resfriada no sistema de resfriamento evaporativo através da passagem da água de circulação pela obstrução do ejetor, poderá percorrer um tanque encamisado para resfriamento indireto de algum alimento líquido ou sólido, como por exemplo, de leite, café, entre outros.

Assim, o objetivo deste trabalho foi construir e avaliar energeticamente um sistema de resfriamento evaporativo utilizando hidroejetor, através do cálculo do parâmetro coeficiente de desempenho (COP) do sistema.

\section{MATERIAL E MÉTODOS}

O sistema de resfriamento evaporativo ensaiado consiste nos seguintes equipamentos: um reservatório de água para resfriamento a baixa pressão, também podendo ser utilizado para termoacumulação; reservatório de água para circulação (volume de $80 \mathrm{~L}$ ); reservatório de água de reposição (volume de $60 \mathrm{~mL}$ ); bomba centrífuga (marca Thebe e modelo Th 16), que faz a circulação da água armazenada no reservatório de circulação até o hidroejetor; hidroejetor, composto com dois compartimentos (convergente e divergente); banho termostático para resfriamento indireto da água de circulação; mangueira de vácuo para conexão do bocal do hidroejetor ao reservatório de resfriamento e uma resistência elétrica, para simulação de carga térmica. sistema.

Conforme mostra a Figura 1, pode ser vista a instrumentação instalada para avaliação do 


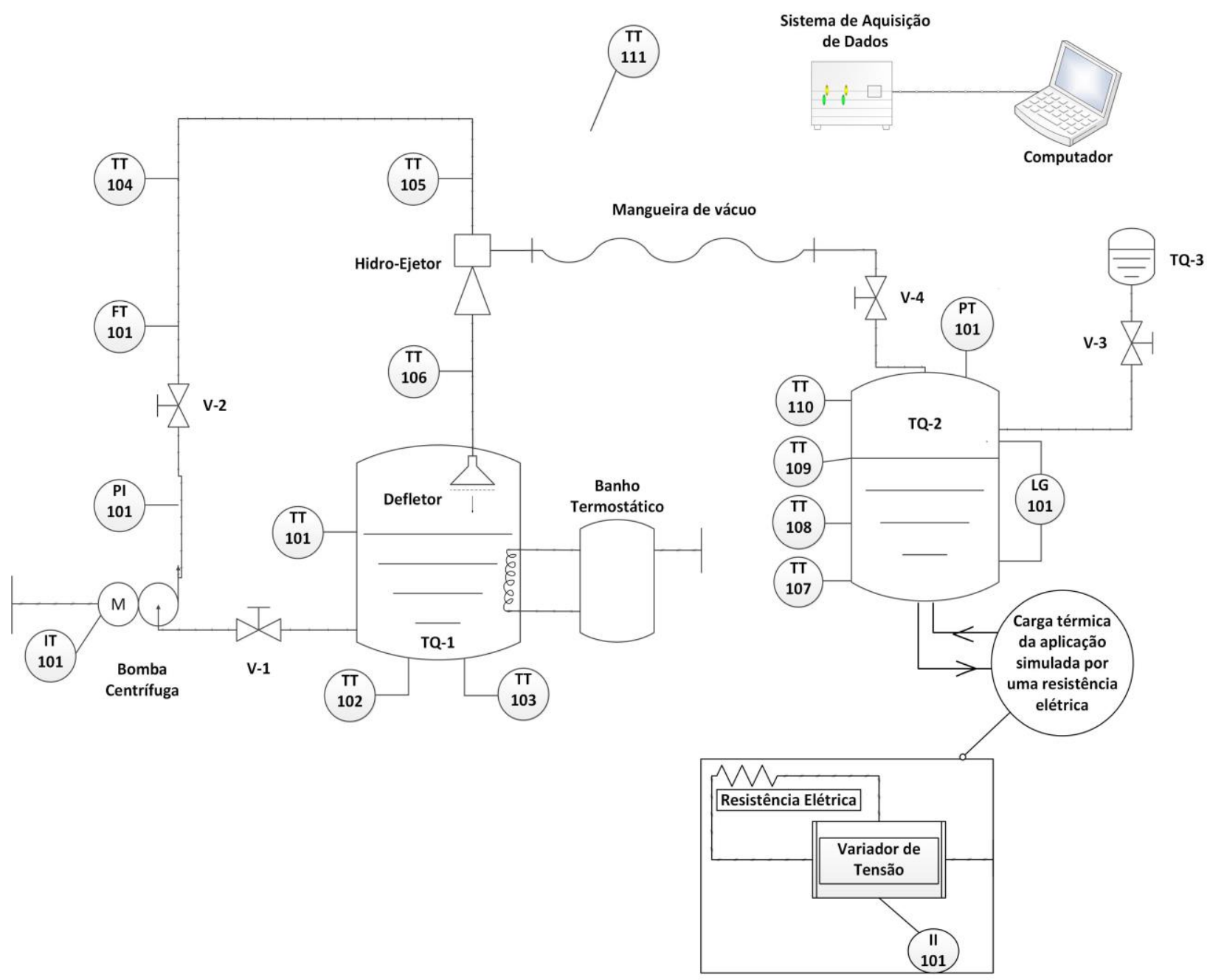

Figura 1 - Esquema instrumental do sistema de resfriamento evaporativo utilizando hidroejetor.

A descrição da montagem e instrumentação são: TQ-1, Reservatório de circulação; TQ-2, Reservatório de resfriamento; TQ-3, Reservatório de reposição; V-1, Válvula esfera na saída do reservatório de circulação; V-2, Válvula agulha após a bomba centrífuga; V-3, Válvula esfera na saída do reservatório de reposição; V-4, Válvula esfera no reservatório de resfriamento; TT 101, Transdutor de temperatura no reservatório de circulação 01; TT 102, Transdutor de temperatura no reservatório de circulação 02 ; TT 103; Transdutor de temperatura no reservatório de circulação 03 ; TT 104, Transdutor de temperatura depois da bomba centrífuga; TT 105, Transdutor de temperatura antes do hidroejetor; TT 106, Transdutor de temperatura depois do hidroejetor; TT 107, Transdutor de temperatura no reservatório de resfriamento 01; TT 108, Transdutor de temperatura no reservatório de resfriamento 02; TT 109, Transdutor de temperatura no reservatório de resfriamento 03; TT 110, Transdutor de temperatura no reservatório de resfriamento 04; TT 111, Transdutor de temperatura no ambiente; PT 101 e PI 101, Transmissor de pressão e Indicador de pressão (Manômetro); IT 101 e II 101, Transdutor de corrente e Indicador de corrente (Multímetro) e FT 101, Transmissor de vazão. 
O sistema foi instrumentado com sensores de pressão (modelo TPI-Press e série 78703); sensores de temperatura (termorresistências do tipo Pt100), com precisão de $0,2{ }^{\circ} \mathrm{C}$ e linearidade $\left(\mathrm{R}^{2}=0,99\right)$; medidor e transmissor de vazão tipo magnético; variador de tensão analógico (modelo W5MT3) e transdutor de intensidade de corrente elétrica com entrada de 0 a 5 A ac e comunicação de saída de 4 a $20 \mathrm{~mA}$. Os dados foram registrados pelo programa Field Chart 1.76 em intervalos de 30 segundos.

De acordo com a configuração do hidroejetor, o mesmo fornece uma queda de pressão quando o fluido percorre o compartimento convergente, onde há o aumento da velocidade e redução da pressão. Como o bocal está conectado ao reservatório de resfriamento pela câmara de sucção, então há a redução da pressão no reservatório de resfriamento. A princípio, ocorre a sucção de ar úmido do reservatório de resfriamento, o que permite que a pressão parcial da água na fase gasosa presente no reservatório de resfriamento seja reduzida, ficando abaixo da pressão de saturação da água líquida. Esse fenômeno leva a evaporação da água presente no reservatório de resfriamento, que pelo processo de transferência de massa e calor provoca o resfriamento da água de resfriamento. Esse ar úmido ou vapor de água a baixa pressão são succionados juntamente do reservatório de resfriamento pela água de circulação e se misturam na câmara de mistura do hidroejetor. Neste local, recuperam a pressão de forma suficiente para equilibrar a pressão atmosférica no difusor divergente, pelo aumento do diâmetro do mesmo, e alcançam o reservatório de circulação.

Os ensaios consistiram em avaliar os efeitos sobre a temperatura da água de resfriamento sob as variações das cargas térmicas e consequentemente a avaliação energética do sistema:

\subsection{Carga térmica}

Após atingir o estado estacionário, na menor temperatura da água armazenada no reservatório de resfriamento, quando o sistema foi exposto as condições operacionais nominais de $4,1 \pm 0,1 \mathrm{~m}^{3} / \mathrm{h}$ e $5 \pm 0,5{ }^{\circ} \mathrm{C}$ para obtenção do menor vácuo, foi avaliado o comportamento da temperatura da água de resfriamento submetida a diferentes degraus de cargas térmicas permanentes pelo acionamento da potência térmica com a resistência elétrica. As diferentes cargas térmicas imposta no sistema foram obtidas pela variação de tensão sobre a resistência elétrica de $20,25,30,40,45$ e $60 \mathrm{~V}$, que resultaram em potências térmicas de 12,$61 ; 27,85 ; 31,14 ; 49,92$, 56,68; e 92,27 Watts, respectivamente.

\subsection{Avaliação energética}

O parâmetro analisado no sistema de resfriamento evaporativo foi o coeficiente de desempenho ou de eficácia (COP) que calcula a razão do efeito desejado pela energia gasta, como mostra a Equação 1, em condições estacionárias:

$$
C O P=\frac{Q_{a}}{W}
$$


Onde:

$\mathrm{Q}_{\mathrm{a}}=$ Potência térmica imposta (ou de resfriamento) a água armazenada no reservatório de resfriamento $(\mathrm{kJ} / \mathrm{s})$

$\mathrm{W}=$ Trabalho fornecido ao sistema (potência do motor da bomba) $(\mathrm{kJ} / \mathrm{s})$

A efetiva Potência térmica imposta $\left(Q_{a}\right)$ foi calculada conforme a Equação 2:

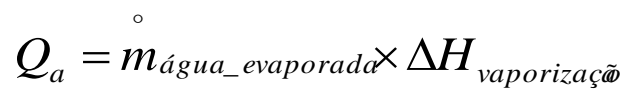

Onde:

$m_{\text {água_evaporada_ }}$ vazão mássica de água evaporada a partir do calor fornecido pela resistência elétrica $(\mathrm{kg} / \mathrm{s})$

$\Delta \mathrm{H}$ vaporização - variação de entalpia específica da água evaporada na pressão e temperatura alcançada (kJ/kg) (Potter e Scott, 2006)

O trabalho fornecido (W) ao sistema de resfriamento evaporativo foi calculado pelo produto da tensão nominal $(220 \mathrm{~V})$, da intensidade de corrente elétrica $(3,15 \mathrm{~A} \pm 0,01)$ e da raiz quadrada de três (motor trifásico), pois ambas permaneceram aproximadamente constante durante o funcionamento do sistema, como mostra a Equação 3:

$$
W=V \times I \times \sqrt{3}
$$

Onde:

V- Tensão (Volt)

I - Intensidade de corrente elétrica (Ampére)

\section{RESULTADOS E DISCUSSÃO}

\subsection{Estudo do comportamento da água de resfriamento quando submetida a diferentes cargas térmicas}

Foram realizados ensaios com aplicações de cargas térmicas na água de resfriamento, por 
meio da resistência elétrica instalada no fundo do reservatório, para estudar o comportamento da água e da fase gasosa contida no mesmo, com precisão de $0,01 \mathrm{~A}$ e $0,5 \mathrm{~V}$, nas condições operacionais nominais de $4,1 \pm 0,1 \mathrm{~m}^{3} / \mathrm{h}$ e $5 \pm 0,5{ }^{\circ} \mathrm{C}$ da água de circulação para obtenção de menor pressão e menor temperatura de resfriamento. Os resultados das temperaturas inicial e após a aplicação da carga térmica, com o processo em regime permanente, podem ser encontrados na Tabela 1.

Tabela 1. Temperatura média atingida pela água de resfriamento $\left({ }^{\circ} \mathrm{C}\right)$ quando submetido a diferentes potência térmicas, nas condições operacionais nominais de $4,1 \pm 0,1 \mathrm{~m}^{3} / \mathrm{h}$ e $5 \pm 0,5^{\circ} \mathrm{C}$

\begin{tabular}{ccc}
\hline $\begin{array}{c}\text { Potência Térmica } \\
\text { Absorvida (Watts) }\end{array}$ & $\begin{array}{c}\text { Temperatura inicial } \\
\text { da água de } \\
\text { resfriamento }\left({ }^{\circ} \mathrm{C}\right)\end{array}$ & $\begin{array}{c}\text { Temperatura final da água de } \\
\text { resfriamento }\left({ }^{\circ} \mathrm{C}\right) \\
\text { após estabilizado }\end{array}$ \\
\hline 12,61 & 10,2 & 11,6 \\
27,85 & 10,2 & 13,3 \\
31,14 & 9,3 & 15,3 \\
49,92 & 11,5 & 20,8 \\
56,58 & 9,7 & 20,7 \\
92,27 & 8,9 & 23,7 \\
\hline
\end{tabular}

Pode-se observar que com o aumento da potência térmica, o sistema se estabilizou em diferentes e crescentes temperaturas da água de resfriamento. Sendo assim, pela perturbação da carga térmica, tipo degrau, observou-se que, quanto maior a carga térmica fornecida, o sistema estabiliza em maior temperatura.

O comportamento crescente da temperatura com o aumento da carga térmica, tende a chegar num ponto em que a quantidade de água evaporada será tão grande que irá atrapalhar a sucção da fase gasosa pelo hidroejetor, possibilitando a ocorrência de desestabilização do sistema. Em consequência da não funcionalidade do hidroejetor, poderá ocorrer o aquecimento da água de resfriamento, caso a resistência elétrica permaneça ligada, até a sua completa evaporação ou poderá ocorrer a inundação do reservatório de resfriamento pela água de circulação através da diferença de pressão que será incialmente gerada.

\subsection{Avaliação do coeficiente de desempenho ou de eficácia (COP)}

O coeficiente de desempenho (COP) foi calculado com fornecimento de trabalho ao sistema de resfriamento evaporativo com uso de hidroejetor de 1200,3 J/s. Os resultados dos COP atingidos pelo sistema com suas respectivas potências térmicas absorvida pela água de resfriamento, podem ser encontrados na Tabela 2. 
Tabela 2. Coeficiente de desempenho do sistema de resfriamento evaporativo com uso de hidroejetor em diferentes potências térmicas absorvidas pela água de resfriamento

\begin{tabular}{cc}
\hline Potência térmica absorvida pela água de resfriamento $(\mathrm{J} / \mathrm{s})$ & $\mathrm{COP}_{\text {atingido }}$ \\
\hline 12,61 & 0,011 \\
27,85 & 0,023 \\
31,14 & 0,026 \\
49,92 & 0,042 \\
56,68 & 0,047 \\
92,27 & 0,077 \\
\hline
\end{tabular}

Observou-se que o COP foi maior quanto maior a potência térmica absorvida pela água de resfriamento. Os baixos valores obtidos na determinação do COP para o sistema de resfriamento em estudo foram esperados quando comparados aos COP de sistemas de refrigeração utilizando ejetor a vapor, visto que o vapor possui característica física superior ao fluido em estado de agregação líquido com maior velocidade de escoamento. Outro fator que pode ter influenciado de forma negativa o COP do sistema foi a utilização da bomba centrífuga que aquecia a água de circulação ao passar pelo seu rotor. Tendo a bomba centrífuga um comportamento não esperado, pode ter se esforçado mais, perdendo a sua eficiência e utilizando uma potência maior para transportar a água. Portanto a energia gasta para o trabalho da bomba centrífuga pode estar superestimado devido seu mau funcionamento.

O sistema em estudo não apresentou um COP elevado, mas quando observado outros sistemas de refrigeração, o mesmo se assemelha aos COP atingidos. Vargas et al. (2009) esperaram um COP de 0,292 para um evaporador com capacidade de $91 \mathrm{~W}$ e com o fluido R141b a uma temperatura de $10{ }^{\circ} \mathrm{C}$, de acordo com as correlações empíricas de Huang e Chang (1999), entretanto o melhor resultado obtido foi um COP de 0,221, sendo assim, 25\% abaixo do esperado, considerando a taxa do fluido secundário através do evaporador de $0,39 \mathrm{~g} / \mathrm{s}$ e com a taxa do fluido principal de $1,68 \mathrm{~g} / \mathrm{s}$. Jain, Agrawal e Pachorkar (2012) relatam que o COP do ciclo de refrigeração assistido com energia solar e com uso de ejetor foi de 0,13 . O sistema foi exposto a radiação solar incidente de $700 \mathrm{~W} / \mathrm{m}^{2}$, capacidade de refrigeração de $5 \mathrm{~kW}$, temperatura de geração de $90{ }^{\circ} \mathrm{C}$, temperatura de condensação de $37^{\circ} \mathrm{C}$ e temperatura de evaporação de $10^{\circ} \mathrm{C}$.

\section{CONCLUSÕES}

Pode-se concluir, para um sistema de resfriamento utilizando hidroejetor, que a crescente potência térmica imposta ao reservatório de resfriamento resulta em temperatura da água de resfriamento diretamente proporcional.

O sistema de resfriamento evaporativo com uso de hidroejetor estudado apresentou um coeficiente de desempenho de 0,077 nas condições operacionais nominais de $4,1 \pm 0,1 \mathrm{~m}^{3} / \mathrm{h}$ e $5 \pm$ $0,5{ }^{\circ} \mathrm{C}$ da água de circulação. Um dos motivos para obtenção do baixo COP está no mal funcionamento da bomba centrífuga usada para bombeamento e circulação da água que passava 
pelo hidroejetor, gerando uma má eficiência do equipamento e portanto uma maior demanda energética para sua operação.

Para sistemas em que há circulação de água em abundância e que o resfriamento pode ocorrer em patamares de temperaturas superiores, o sistema tende a ser bom, pois não precisaria alcançar tão baixas pressões e consequentemente poderia ser usada a água de circulação na temperatura ambiente.

\section{AGRADECIMENTO}

À Capes

\section{REFERENCIAS}

CAVALHEIRO, D.; SCHMIDT, F. C.; RODRIGUES, L. G. G.; SIGA, C.; LEITEMPERGHER, F.; LAURINDO, J. B. Processing of perna perna mussels using integrated process of cooking and vacuum cooling. J. Food Process Eng., ISSN 1745-4530, 36, 192-201, 2013.

HUANG, B. J.; CHANG, J. M. Empirical correlation for ejector design. Int. J. Refrig, 22, 379388, 1999.

JAIN, A.; AGRAWAL, S. K.; PACHORKAR, P. Exergy Analysis of the Solar-Driven Ejector Refrigeration System. IOSR J. Mech. Civil Eng. (IOSR-JMCE). ISSN: 2278-1684 Volume 3, Issue 3, PP 30-36, 2012.

RODRIGUES, L. G. G.; CAVALHEIRO, D.; SCHMIDT, F. C.; LAURINDO, J. B. Integration of cooking and vacuum cooling of carrots in a same vessel. Ciênc. Tecnol. Aliment. ISSN 0101-2061 Campinas, 32(1): 187-195, jan.-mar, 2012.

VARGAS, L. C. P.; BARBOSA, C. R. F.; FONTES, F. A. O.; ALMEIDA, I. M. G. Projeto do ejetor de um sistema de refrigeração por jato de compressão de vapor. IV Congresso de Pesquisa e Inovação da Rede Norte e Nordeste de Educação Tecnológica. Belém - PA, 2009. 